\title{
Modelling the Dynamics of Internet Adoption
}

\author{
Mohd Nazri Mahmud \\ School of Electrical and Electronic Engineering, Universiti Sains Malaysia \\ Engineering Campus, Seri Ampangan, 14300, Nibong Tebal, Penang, Malaysia \\ Tel: 6-04-5996059Ｅ-mail: nazriee@eng.usm.my
}

\begin{abstract}
The adoption of the Internet in societies is becoming more important as more and more public and business services are delivered via the Internet. Understanding the dynamics of the adoption is vital in developing policies to stimulate greater adoption. This paper highlights the dynamics of internet adoption in a general society based on the segmentation of the society into subcultures according to their respective affinities towards Internet adoption. System dynamics model are built to reveal the dynamics.
\end{abstract}

Keywords: Internet Adoption, System dynamics

\section{Introduction}

The internet is prevalent as a medium of service delivery for public and businesses. The success of e-government initiatives in public service delivery for example depends on the adoption of the Internet among the citizen. Policy makers are finding ways to increase the adoption especially in developing countries where adoption mostly concentrates in the urban areas. It is important to recognize the difference among the society in terms of their affinity towards Internet adoption. This study takes a segmented view of the society to assist in developing a system dynamic model which is used in investigating the dynamics of the adoption. The system dynamics modeling approach is employed here in order to give a holistic view of the dynamics of the Internet adoption business.

\section{Segmentation of the society}

\subsection{Categorisation of potential adopters}

The categorisation of adopters encompasses demographic, socioeconomic and regional characteristics that have been commonly included in Internet demand studies (Deaton, 1992), (McCraken, 1988). Such a market-based segmentation implies an underlying assumption founded on standard economic theory of utility maximisation that concerns with individual's demand for goods (Liebowitz and Margolis, 1994).

Generally, cost-conscious consumers make their Internet subscription decision by comparing costs and benefits from such a connection based on utility maximisation under income constraint. This means it is a choice between spending their disposable income for optional needs to acquire Internet connection or spend on other optional needs such as entertainment (InfoSoc Malaysia, 2000). Subscription is made if the utility of an Internet connection exceeds the utility from other alternatives such as a post-mail or a fax. Utility is also a function of many factors such as content appropriateness and security. This decision behaviour of the potential Internet users is an important dynamic to be captured in the model.

The standard utility perspective also recognises the elasticity of demand. Price elasticity depends on the existence of substitutes, the importance of the product or service in the consumer's budget and the time period under consideration. (Villasis, 1996, p.71). It also relates to other types of elasticities namely income, cross-price and supply elasticities. Cross-price elasticity highlights the important dynamics between prices of complements and substitutes (e.g. computers, access lines, post-mail, faxes) and subscription to Internet.

This utility-based view of the users means that subscription to Internet is not a one-way process. There is a possibility of attrition especially when such subscriptions are based on dual-pricing system, whereby charges comprise of two components: access and usage. For example, a moderate Internet user may subscribe on the basis of low usage fees but discontinue later on because their low usage levels do not justify the high access fees (Lemon and Winer, 1995).

Apart from the consumers, firms are also important actors in the Internet market. These are the Internet service providers (ISPs), Application Service Providers (ASPs) and Content Service Providers (CSPs). The first one provides connectivity while the other two provides applications such as financial services and content such as digital movies.

Drawing upon the theory of the firm, these providers follow the standard profit-maximizing and price-taking behaviour 
by optimising their supply (Bental and Spiegel, 1995). This price taking behaviour is visible in developed Internet market such as the US where - unlike the less developed market such as Africa- the providers exceeds several hundreds (ITU, 2001). Thus, the Internet market increasingly becoming close to perfectly competitive condition. This theory and evidence inform us the competitive dynamics of the Internet market. With increasing market potential, the model shall exhibit the proliferation of ISPs, ASPs and CSPs.

\subsection{Causal loop diagrams}

The society is divided into eight segments based on their characteristics with respect to Internet adoption. This is shown in Table 1 below. Modeling the factors in the subsystems involves the formation of Causal Loop Diagrams to represent the dynamics and causality between variables. The Causal Loop Diagram for the Imitators subsystem is given in Figure 1 .

The existing subscribers influence the potential "imitators" through "word-of-mouth". As the population of subscribers increases, the "word-of-mouth" effect increases and causes the subscription rate to increase even further. The degree of influence also increases with subscriber base as "network externalities" increases the perceived value of the Internet when more of their close friends and families join the network. This represents a positive reinforcing feedback loop, labeled as "word-of-mouth" in the diagram.

On the other hand, if the population of imitators is finite and/or when the rate of increase in the number of potential imitators is lower than the subscription rate, an increase in the latter would reduces the population of the former. This in turn reduces the subscription rate and thus provides the balancing feedback loop to the subsystem.

Realistically, not all of these encounters involve existing subscribers. To take this into account, the numbers of encounters with subscribers is determined by the probability of encountering an existing subscriber. Similarly, the probability of encountering a subscriber is also determined by the total number of existing subscribers and the country's total population. Not all of these encounters results in Internet subscription. This is determined by the Influential Encounter fraction; a probability that an encounter will result in subscription.

The second subsystem models the Internet cost conscious segment and focuses on modeling the effects of economies of scale, competition, Internet cost and income. The Causal Loop Diagram is given in Figure 2. As the subscriber population increases, the marginal cost to provide Internet service decreases due to economies of scale. This reduces the Internet cost to consumers and increases the number of subscriptions, which increases the total subscriber population.

Similarly, as the subscriber population increases, the Internet sales revenue also increases. Such a signal of market potential attracts more Service Provider to enter the industry and increases the competition that drives the price down. Consequently, a reduction in price encourages more cost-conscious consumers to subscribe. The dotted lines in the diagram represent delayed effects as it takes time for a new entrant to enter and affect the prices.

The Internet cost is affected by both the economies of scale and competitive forces. The value is the minimum of the two as some competitors may give substantial price reduction even if they have not acquired the scale economies. When there is no competition, the only provider is the state-owned incumbent that by default has a substantial scale advantage to reduce the price. In the absence of a monopoly, the resulting competitive forces drive the price down.

However, the number of service provider cannot rise infinitely. As the number of competitor increases, sales revenue for individual provider decreases. This reduces the number of providers that can profitable compete in the market. Thus, we can expect to see the maximum number of providers as the market matures.

Similar to the previous subsystem, if the population of Internet Cost Conscious is finite and/or when its rate of increase is lower than the subscription rate, the number of subscription by this segment will approach saturation. This in turn reduces the subscription rate and thus provides the balancing feedback loop to the system.

Similar to the previous subsystem, if the population of Internet Cost Conscious is finite and/or when its rate of increase is lower than the subscription rate, the number of subscription by this segment will approach saturation. This in turn reduces the subscription rate and thus provides the balancing feedback loop to the system.

The third subsystem involves dynamics that resembles that of Internet Cost Conscious subsystem. The disposable income for this group needs to be lower than ICC depending on the context. The main Causal Loop Diagram is given in Figure 3 below.

The Causal Loop Diagram for the fourth subsystem is given in Figure 4 below. Again, the subsystem mimics the previous two subsystems albeit a much lower disposable income for this group. The fifth subsystem which represents the dynamics in the underserved areas focuses mainly on the capacity acquisition in the presence of a waiting list. The subsystem considers only those who can afford to subscribe. Poor people from this area are put under another group that needs collective access and special training program. The Causal Loop Diagram is given in Figure 5.

Due to infrastructure unavailability, the orders are put on a waiting list and labeled as "waiters". The greater the 
population in this area, the higher the number of households without access lines. New order increases depending upon the fraction of the household placing orders. These new orders become new waiters who add to the existing waiting list. The longer the waiting list and the rate of increase in new order, the higher the order forecast would be. When the financial resources are abundant, the order forecast dominates the decision on the number of capacity to be added. In many cases, countries face capital constraints to providing access in remote areas [28]. The more capacity added, the more additional capacity available for serving waiters. However, higher number of waiters served results in lower capacity left to fulfill new orders.

The final subsystem highlights the dynamics that occur in the educational pipeline that can have long term influence on the Internet penetration level. The higher the educational achievement translates to higher potential of becoming Internet users. An Early exposure to Internet in the educational sector also increases the likelihood of future usage. The causal loop diagram given in Figure 6 also captures the dynamics that lead to the formation of the group who are considered as marginalised in ICT. The formation of the marginalised group occurs when children either do not attend any formal education and become illiterate or drop out of school early without undergoing any special program to acquire any IT skill. Thus, they are unable to use the services provided via the Internet. The higher the population of marginalsied society, the less capable a country is with respect to the knowledge economy and this causes a cycle of poverty.

\section{Case application}

This section shows how the model can be tailored to a specific country's application and build confidence in its applicability to policy experimentation. The platform model has been applied to the Malaysian context.

The Internet started in Malaysia in 1988 when the Malaysian Institute of Microelectronic Systems (MIMOS) set up a university computer network called Rangkaian Komputer Malaysia ("Malaysian Computer Network), RangKom, which consisted of 4 dial-up lines to Australia, Holland, Korea, and the US. It offered e-mail and news group services. This dialup infrastructure was replaced by a satellite link to the US, and Malaysia MIMOS established the Joint Advanced Integrated Networking (JARING) as an Internet Service Provider (ISP) and remained the sole provider until Telekom Malaysia's TMnet entered in 1996. The market remained a duopoly until 2000 when additional licenses were issued (ITU, 2001).

There is a great concern within the Malaysian government about the "Digital Divide", particularly in differences in access between urban and rural area. The limiting factor is the low level of personal computers penetration. The cost of Internet access including a PC purchase is $88 \%$ of the rural household disposable income for optional needs. The biggest bottleneck however is the fixed telephone lines penetration. 37\% of households do not have telephone and in 2000 the waiting list was 98,000 (ITU, 2001). It is too costly to serve those still without home telephones. Based on the information and detailed data, the model was simulated and the following penetration characteristics in Figure 7 was observed between 1990 to 2002 .

The model follows closely the level of penetration up to 1997 when a substantial underestimation occurs. The reason is that the model does not take into account any policy intervention during the time period. The government regulated the price for Internet Access to be lower than the voice telephone calls. Such a subsidy through partial-state-owned incumbent, Telekom Malaysia, result in the proliferation of Internet Subscription in Malaysia more than what it would have been under market forces (or failure). This example highlights the important transition step from laboratory to decision table. A modeler needs to incorporate the contextual dynamics that can have a long term impact into the basic model. This price-setting intervention is incorporated as a step input starting at the corresponding year. Resimulation results in an improved fit until year 2000 when the model again underestimates the growth. See Figure 8.

A modeler continues to check with policy makers if there were any policy intervention that must be included in the model. In the case of Malaysia, there were many policies and programmes launched in 1999 that improved the penetration. (Note 1)

\subsection{What-if scenario}

A model can only be applied to test scenarios and policy alternatives when the end user has confidence in the behaviour of the model. This does not mean that the model must achieve $100 \%$ historical fit. This section serves only to illustrate how the model can be used for policy experiments. It does not guarantee accuracy as many dynamics are reserved for future development. For example, lowering the price of Internet by subsidies can increase the level of penetration but also create other consequences. Policy makers and analysts can use the system dynamics model to see the impact of such policy on other areas of policy (e.g. competition policy). Figure 9 shows an example of such a use.

The model shows that by 2003, the Malaysian Internet industry could have at least eight service providers. On the other hand, the model shows that due to price regulation 1996, there are only 2 providers by 2003 . This is because the revenue per service provider is lower at lower price and do not attract many firms to enter the market. In fact, until 2000 the Malaysian market remained a duopoly with Telekom Malaysia controlling 70\% of the market (ITU, 2001). 


\section{Conclusion}

The study builds upon the existing literature to reveal the factors, components and the underlying dynamics that involve in the Internet penetration process. In doing so, it shows how the dynamics and complexity of the interactions can be modeled to give a holistic view of the situation to policy makers. In particular, the Causal-Loop diagramming and time-series plot helps understanding of the process and consequences. The dynamic behaviour of a system can be understood by looking at the time plots and relating the time plots to the causal loop diagram.

As the study seeks policy application, the model has been taken from a generic level to a country specific application in order to show how the transition can gain acceptance by tailoring the model to include contextual dynamics. Due to the holistic view of the approach, a system dynamic model is capable of showing how policy can interact with one another as exemplified by price-lowering subsidies and competition policy. Interaction across many elements also presents policy makers with visual representation of the possible consequences. Therefore, this modeling approach and the generic model have future potential for policy application. However, the model must include more case applications in order to gain confidence. In particular, the parameter estimation can be improved further by including more time-series data. There are variables such as demand elasticity which I did not have access to and can be included in the future.

In further research, it would be useful to conduct a random survey of both Internet users and those not connected to better understand the reasoning behind consumer choices. Additionally, it is useful to incorporate user retention and attrition dynamics to the model.

\section{References}

Bental, B and M. Spiegel. (1995). Network Competition, Product Quality, and Market Coverage in the Presence of Network Externalities. Journal of Industrial Economics 43(2). pp. 197-208.

Deaton, A. (1992). Understanding Consumption. Oxford: Clarendon Press.

InfoSoc Malaysia. (2000). Discussion paper on Access and Equity: Benchmarking for Progress. Available: http://www.nitc.org.my/resources/INFOSOCMalaysiaRapReport.pdf

ITU. (2001). Internet Diffusion in South East Asia. ITU Internet Case Studies. Geneva.

Lemon, Katherine, R.S. Winer. (1995). A Model of Customer Retention for New-to-the World Product and Services. Working Paper, Duke University, Durham, NC.

Liebowitz, S.J. and S.E. Margolis. (1994). "Network Externality: An Un- common Tragedy,” The Journal of Economic Perspectives, 8: 133-50.

McCraken, G. (1988). Culture and Consumption: New Approaches to the Symbolic Character of Consumer Goods and Activities. Indianapolis: Indiana University Press.

Villasis, S. J. (1996). An Optimal Pricing Mechanism for Internets End User's [On-line], University of Idaho. Available: http://www.uidaho.edu/ econ/svthes.pdf

\section{Notes}

Note 1. In October 1999, a PC Ownership Campaign was introduced with government loan and allowing citizen to withdraw their retirement (Employee Provident Fund) contribution to purchase PCs. 'One Home One PC' campaign offers lower-priced PCs at special fairs. ISps have offered lower-priced PC upon signing up for Internet Service.

Table 1. Potential Subscribers Categories

\begin{tabular}{|l|l|}
\hline \multicolumn{1}{|c|}{ Categories } & \multicolumn{1}{c|}{ Characteristics } \\
\hline Immediate Adopters & $\begin{array}{l}\text { The first group of people to subscribe when the Internet was } \\
\text { first available. It represents some of university graduates, } \\
\text { researchers and teleworkers. They see the value for money of } \\
\text { the Internet }\end{array}$ \\
\hline Imitators & $\begin{array}{l}\text { Subscribe to the Internet after being influenced by the } \\
\text { "innovators" through social encounters. They either were not } \\
\text { aware of the Internet or did not see the value until many people } \\
\text { around them subscribe. Able and/or willing to spend their } \\
\text { money on computers and the Internet after being convinced on } \\
\text { the benefits. }\end{array}$ \\
\hline
\end{tabular}




\begin{tabular}{|l|l|}
\hline Internet-Cost-Conscious & $\begin{array}{l}\text { Possess access lines and computers but not yet subscribe to } \\
\text { Internet due to an unfavourable perceived value of the Internet } \\
\text { and/or under income constraint }\end{array}$ \\
\hline Computer-Cost-Conscious & $\begin{array}{l}\text { Have access lines but do not have computers due to } \\
\text { unfavourable perceived value of them and/or are under income } \\
\text { constraint. Usually entertainment supersedes PC purchase. They } \\
\text { occasionally use Internet in Cybercafes. }\end{array}$ \\
\hline $\begin{array}{l}\text { Access-Line-Cost-Conscio } \\
\text { us }\end{array}$ & $\begin{array}{l}\text { Have no access line or a computer due to an unfavourable } \\
\text { perceived value on both and under income constraint. }\end{array}$ \\
\hline Underserved Areas & $\begin{array}{l}\text { People living in remote areas currently not covered by access } \\
\text { infrastructure. Consists of a medium-income, low-income and } \\
\text { severely poor people. Unlike the last two, the first group can } \\
\text { afford the access line, computer and Internet such as local shop } \\
\text { owners and estate plantation owners. }\end{array}$ \\
\hline Education Pipeline & $\begin{array}{l}\text { Those who are still in school either at primary, secondary or } \\
\text { tertiary level. }\end{array}$ \\
\hline Marginalised Society & $\begin{array}{l}\text { Those with no formal education, illiterate and some primary } \\
\text { school drop-outs. }\end{array}$ \\
\hline
\end{tabular}



Figure 1. The imitators Subsystem 


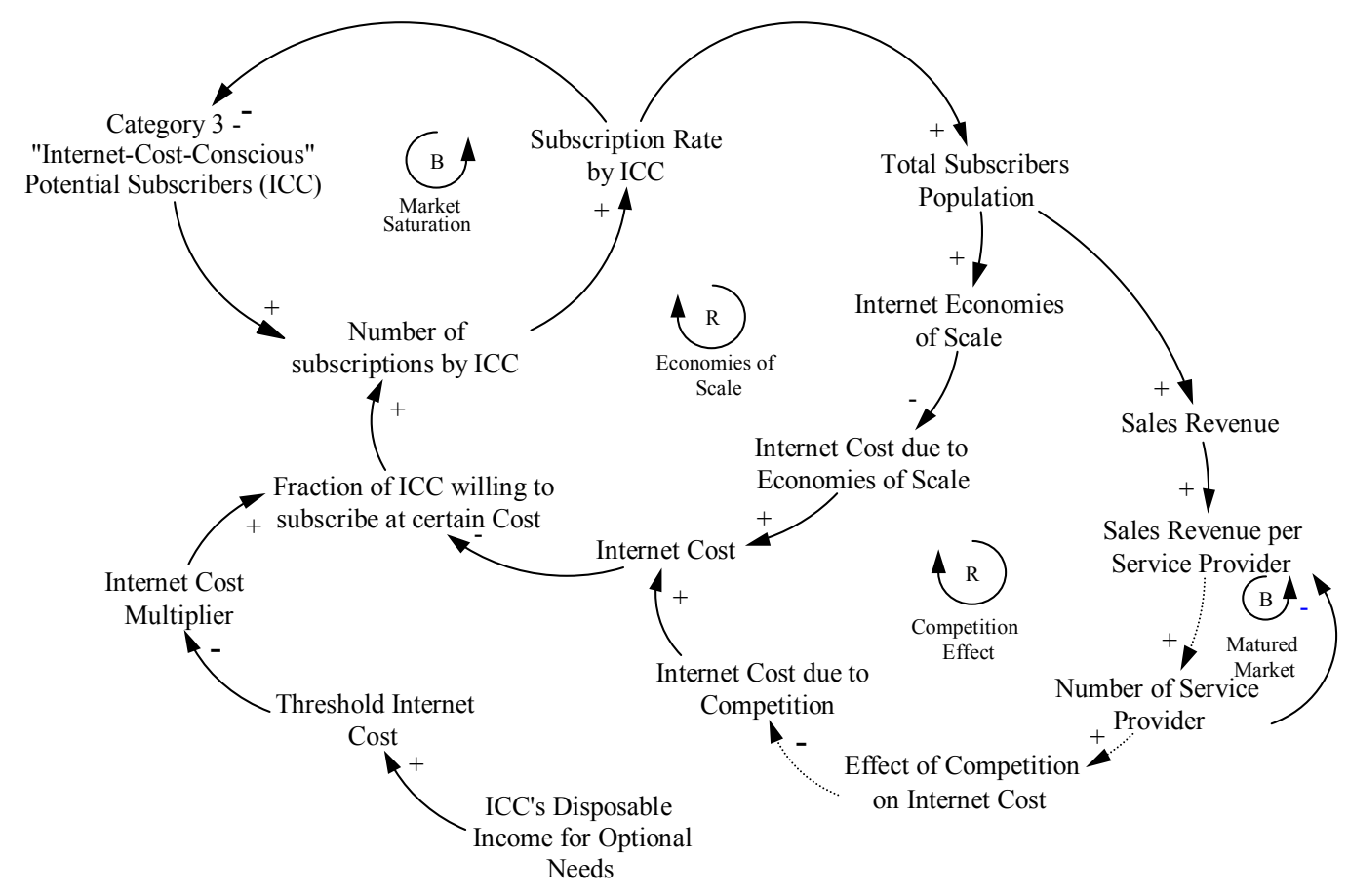

Figure 2. The Internet Cost Conscious Subsystem

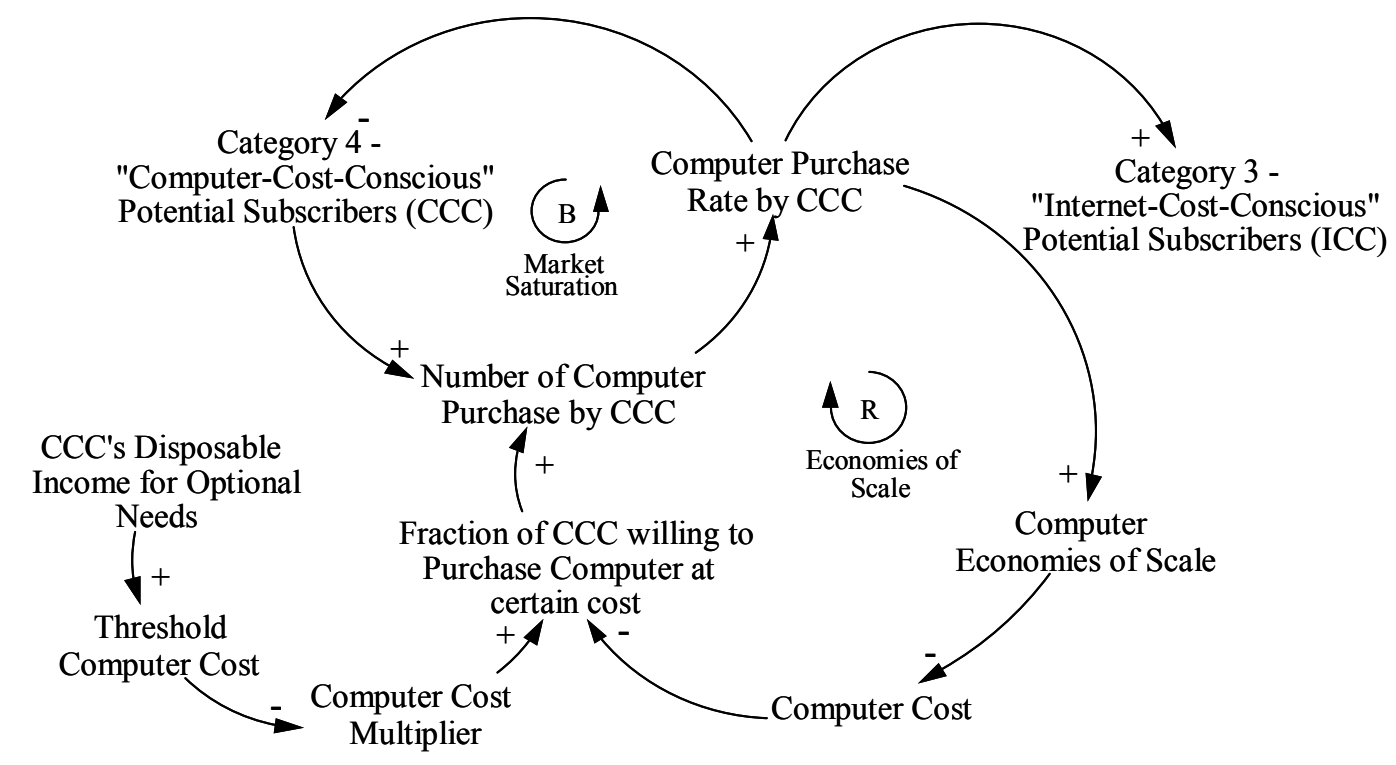

Figure 3. The Computer Cost Conscious Subsystem 


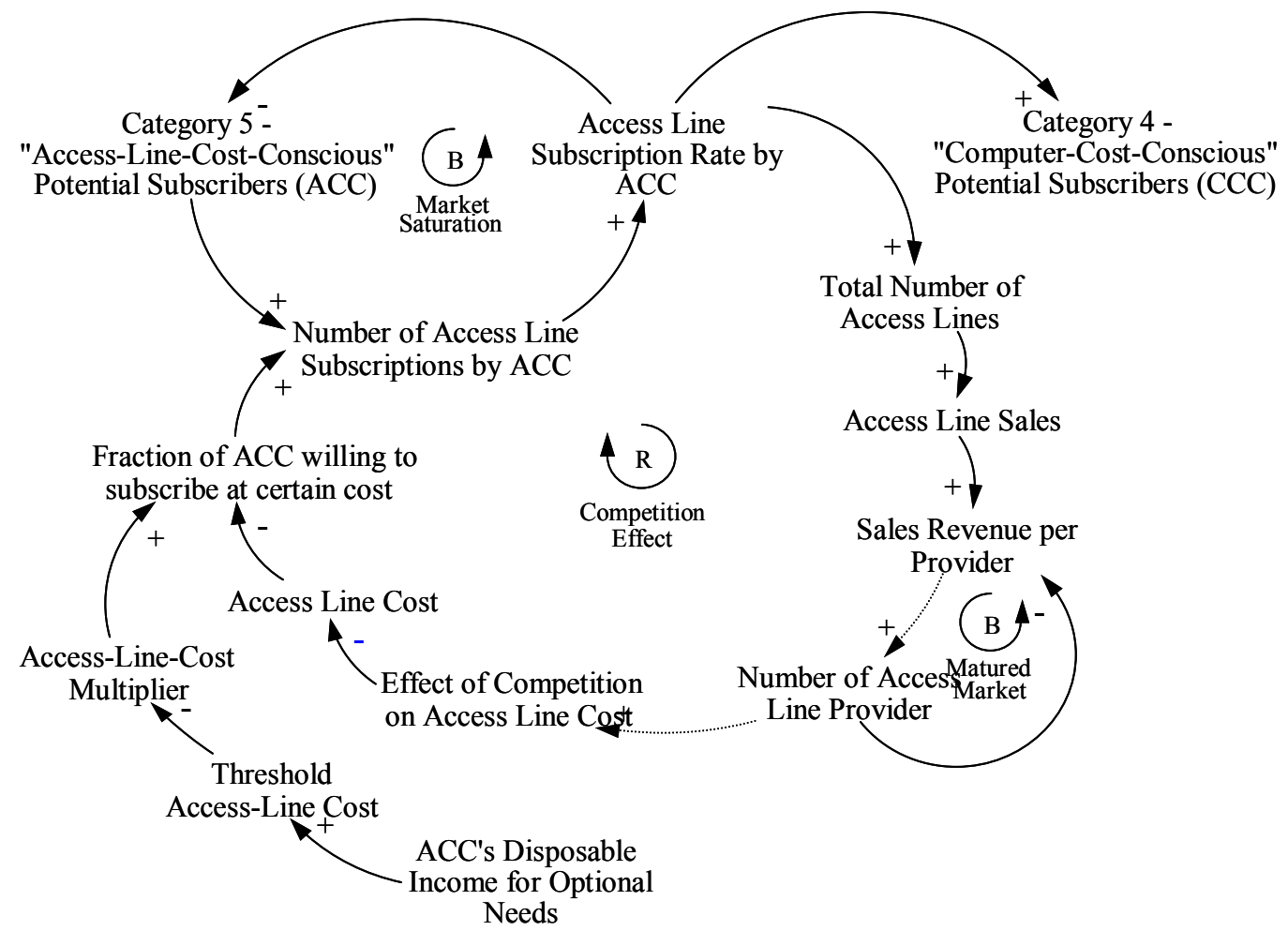

Figure 4. The Access Line Cost Conscious Subsystem

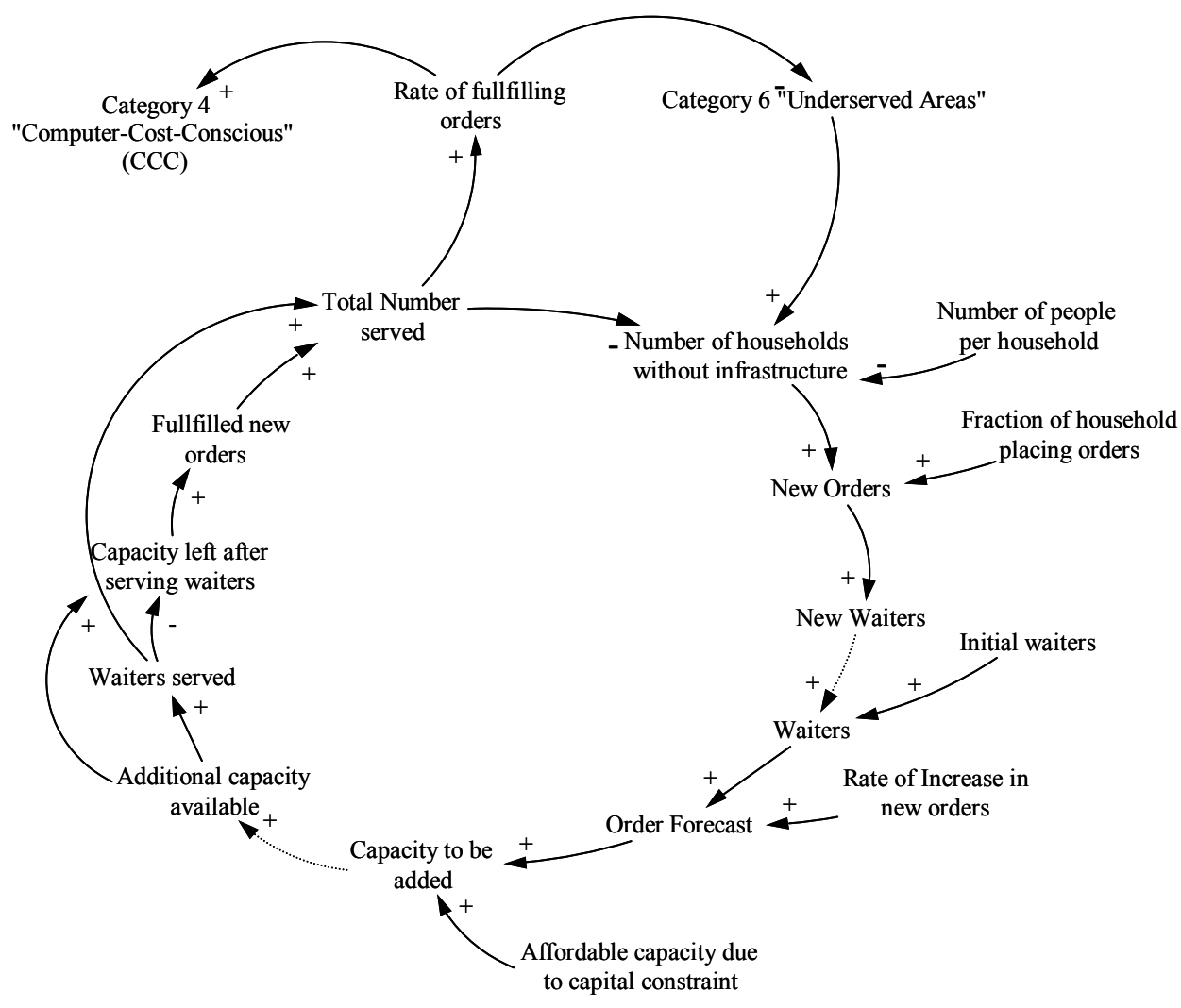

Figure 5. The Underserved Area Subsystem 


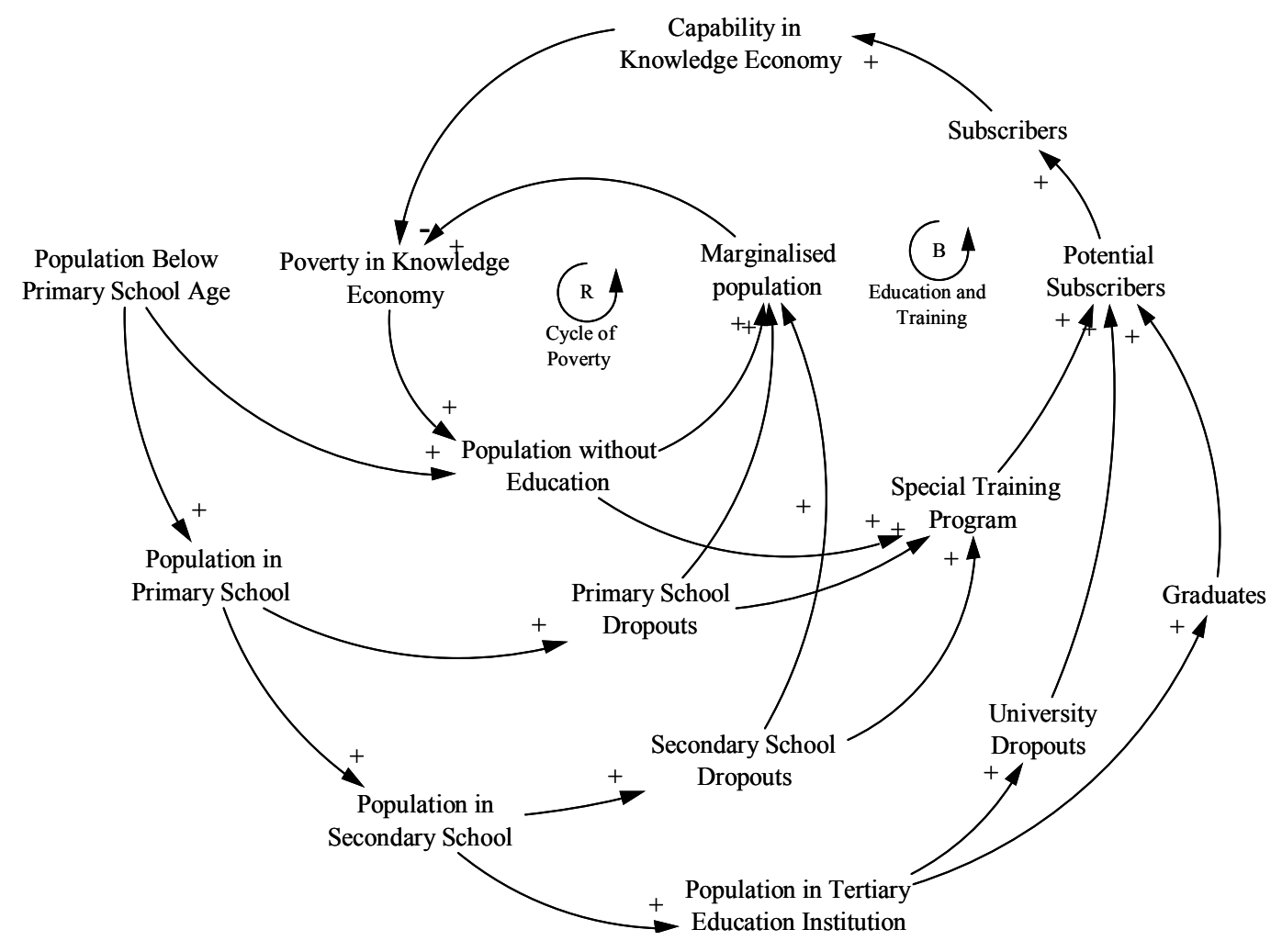

Figure 6. The Educational Subsystem

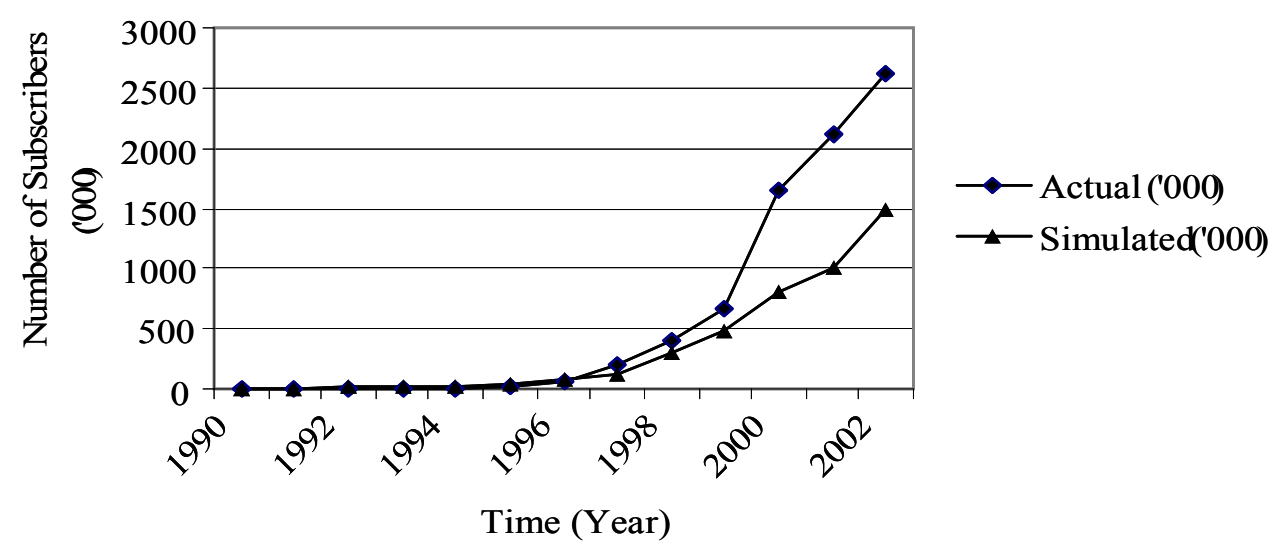

Figure 7. The Malaysian Internet Penetration 


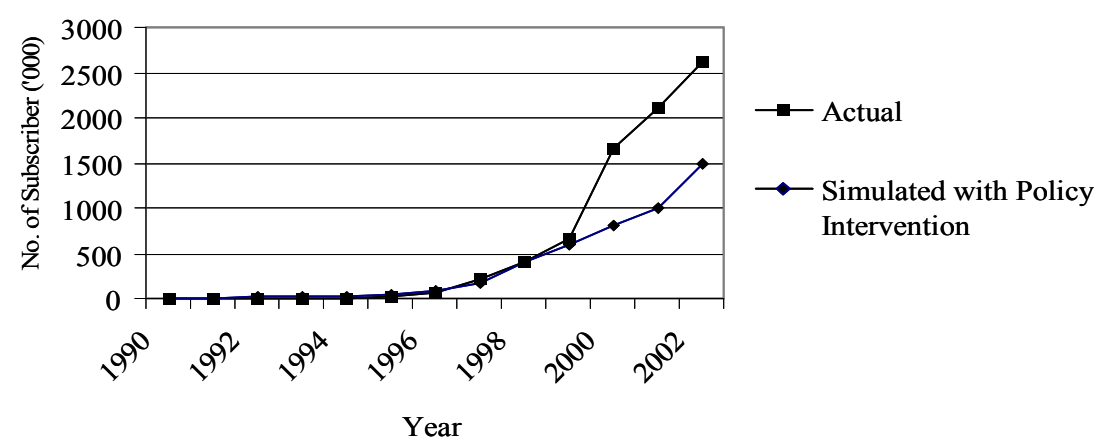

Figure 8. The Malaysian Internet Penetration under Policy Intervention

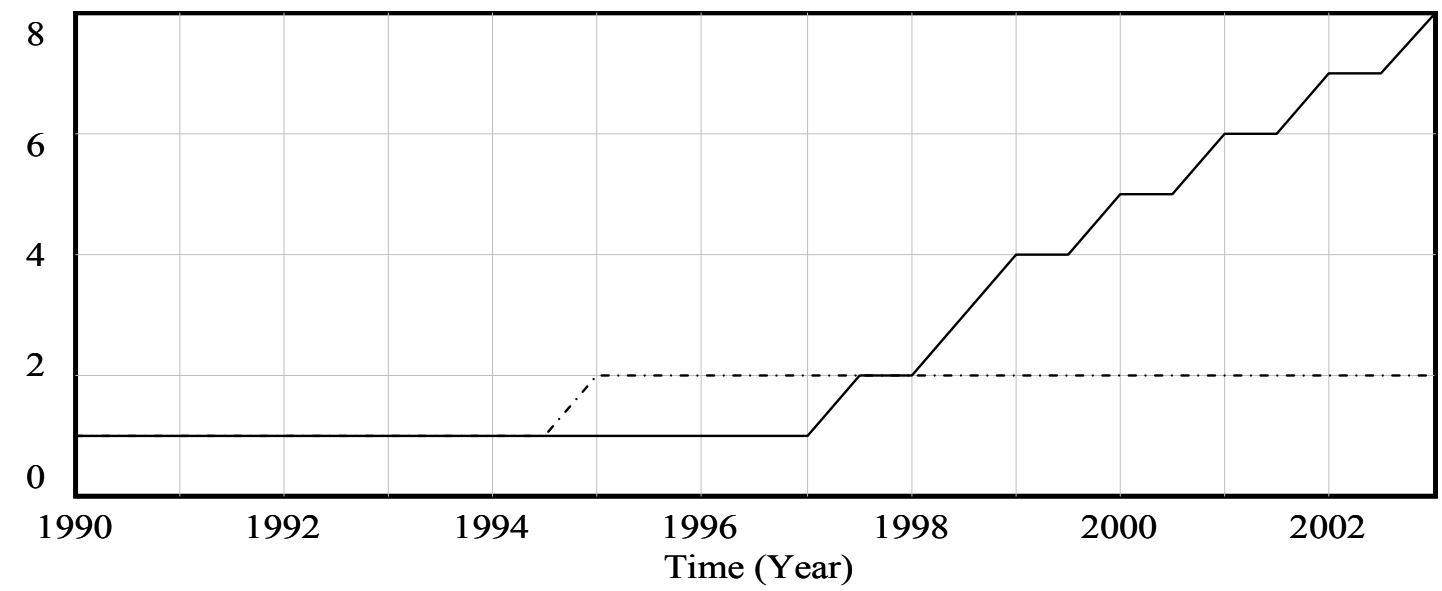

Number of Service Provider : with subsidy

Number of Service Provider : no subsidy

Figure 9. The Number of Service Providers in the Malaysian Internet Market 